\title{
HumanConnect: Scholarships in Science, Technology, Engineering and Math
}

\section{Dr. Howard L. Greene, Ohio State University}

Howard L. Greene directs K-12 Education Outreach for the College of Engineering at The Ohio State University, bringing university research and teaching intersections to the K-12 community, especially those underserved and/or underrepresented. Prior to Ohio State, Dr. Greene worked for 12 years in medical device development and later in STEM education and outreach at Battelle in Columbus, Ohio. Prior to Battelle, Dr. Greene was a professor of Electronics Engineering Technology at DeVry University in Columbus. Dr. Greene received the Ph.D. and M.S. degrees from The Ohio State University in Biomedical Engineering and Electrical Engineering, respectively.

\section{Dr. David L. Tomasko, The Ohio State University}

David Tomasko is a Professor of Chemical \& Biomolecular Engineering at The Ohio State University. He also serves as Associate Dean for Undergraduate Education and Student Services for the College of Engineering

\section{Rachel Tuttle, The Ohio State University}

Rachel serves as the Humanitarian Engineering Scholars Program Manager and an Engineering Undeclared Academic Advisor at The Ohio State University. Prior to working at Ohio State, Rachel worked in Residence Life at both Case Western Reserve University and the University of Virginia. Rachel received her Masters Degree in Higher Education and Student Affairs at the University of South Carolina and her Bachelors Degree in Biology from Bowling Green State University.

\section{Dr. Jan Upton, Institutional Research Consultants, Ltd.}

Jan Upton is the Founder and President of Institutional Research Consultants, Ltd., a program evaluation research firm located in Columbus, Ohio that provides services primarily to grant-funded projects in the following areas: STEM, reading, at-risk students, and teacher professional development. Dr. Upton completed Ph.D. and M.A. degrees in sociology at the University of North Carolina at Chapel Hill where her area of specialization was social stratification (race, class, and gender studies). 


\title{
HumanConnect: Scholarships in Science, Technology, Engineering and Math
}

\begin{abstract}
$\underline{\text { Abstract }}$
The Ohio State University (OSU) offers 17 living-learning "Scholars Programs" organized around diverse areas of interest. Students apply as a part of their university application and are selected based on academic qualifications and demonstrated interest in the particular theme. They commit to participate in scholars activities for their first two years on campus. Scholars live together, study together and take advantage of a host of other thematic supports designed to improve academic success and retention. This S-STEM project "HumanConnect" is aligned with the Humanitarian Engineering Scholars (HES) program in the College of Engineering and supports scholarships of up to 4 full years for academically talented students who demonstrate financial need, enabling them to enter the STEM workforce or graduate school following STEM degree completion. Our two main goals are to 1) Positively impact the retention and graduation of Engineering students with financial need and 2) Improve academic performance relative to a control group (selected from another scholars' community, Green Engineering Scholars or GES).

In the first year of the award (2013-14), scholarships were granted to a first cohort of 15 students (11 first year and 4 second year). In the second year of the award (2014-15), a second cohort of 15 freshmen HES students was awarded scholarships before these students accepted admission to OSU, relying on high school GPA and standardized test scores to determine academic qualification and significant unmet financial need based upon the FAFSA and in light of other sources of aid.
\end{abstract}

Results show that overall retention in engineering and at OSU was high for both recipient and control groups (90\% for HES and $91 \%$ for GES). By comparison, overall first year retention in the College of Engineering was $81 \%$ for 2013-14. HES Cohort 1 students were more likely $(80 \%)$ to meet the 3.0 GPA requirement than the corresponding GES group (67\%). Higher average GPA for both HES cohorts (3.16) versus GES cohorts (3.01), suggest that the scholarship may have pushed recipients to achieve as part of maintaining eligibility. The scholarship appeared to reduce participants' need for outside employment. None of the HES Cohort 2 students reported holding a job. Of the Cohort 1 students who responded to both the Year 1 and Year 2 surveys, 63\% reduced the number of hours they worked in Year 2. Overall, $69 \%$ of HES respondents indicated that the scholarship had enabled them to reduce the number of hours they worked each week while only $33 \%$ of GES students said this about other scholarships they received.

Key outcomes include HES students (combined Cohorts $1 \& 2$ ) attributing positive impacts on their academic performance to the scholarship (94\%) and to aspects of the HES program overall—including being in a living-learning community and a first-year engineering cohort $(100 \%)$. 
HES Cohort 2 respondents said that receiving the scholarship was a key factor in their decision to attend OSU and participate in Humanitarian Engineering (83\%).

Finally, HES students reported experiencing lower stress due to financial issues. HES students also reported that the scholarship allowed them to pursue research or service learning opportunities (75\% for HES vs $0 \%$ for control, p less than 0.05 ) and devote more time to explore graduate study (55\% for HES vs $0 \%$ for control, p less than 0.10 ).

In summary, the HumanConnect Program appears to be meeting its programmatic goals of retention and improved academic performance, while qualitatively lowering the financial stress of participants.

\section{$\underline{\text { Introduction }}$}

In autumn 2013, the OSU received an S-STEM Award (DUE-1259709) over 5 years (2013-18). This communication summarizes the findings after the first two years of the grant (2013-14 and 2014-15).

NSF has long realized the importance of recruiting students to STEM disciplines, mentoring and supporting them through degree completion, and partnering with employers to facilitate student career placement in the STEM workforce. Through the S-STEM Program ${ }^{1}$, NSF makes grants to institutions of higher education to support scholarships for academically talented students demonstrating financial need, enabling them to enter the STEM workforce or STEM graduate school following completion of an associate, baccalaureate, or graduate-level degree in science, technology, engineering or mathematics disciplines.

The objectives of the S-STEM program are to "improve educational opportunities for students, increase retention of students to degree achievement, improve student support programs at institutions of higher education and increase numbers of well-educated and skilled employees in technical areas of national need"1.

Over the past 2 decades, the College of Engineering at OSU has become increasingly aware of the need for students to connect with faculty, each other and to the engineering discipline outside of the classroom. As part of an effort to improve retention and maximize student success, our response has been to create living-learning communities, called "Scholars Communities" at OSU. University-wide, OSU offers 17 Scholars Programs organized around diverse areas of interest. Students apply as a part of their university application and are selected based on academic qualifications and demonstrated interest in the particular theme. They commit to participate in scholars activities for their first two years on campus. Scholars experience a host of thematic supports that are designed to improve their academic success and boost retention. These communities encourage the formation of deep personal and professional relationships that extend outside the classroom, positioning students for success as they work together in groups to study, complete project work, participate in co-curricular activities and discuss broader issues. In addition to a common living arrangement, scholars experience their first year engineering 
courses as a common cohort, attend a thematically linked weekly seminar, have a dedicated scholars' community advisor and engage in volunteer service and field trip venues that give the community theme a broader context.

Engineering programs are rigorous and demanding, from which it is difficult for all but the most well-adapted students to graduate in four years without the assistance of support structures. Scholars' communities integrate this support into a very natural context (one's living arrangement) that makes it easy, natural and 'socially acceptable' for one to participate. The relationships that are formed are not only functional, but lasting. The primary programmatic emphasis for Scholars is during the first two years, while relationships are forming, but they continue to benefit students throughout their education.

Presently, the College of Engineering supports two scholars' communities, "Green Engineering Scholars (GES), a community that embraces the basic tenets of environmental and social responsibility and Humanitarian Engineering Scholars (HES), a group with a very deep-seated desire to use their engineering skills to directly improve the wellbeing of underserved populations. This S-STEM project "HumanConnect" is aligned with the HES program and supports scholarships of up to 4 full years for academically talented students who demonstrate financial need, enabling them to enter the STEM workforce or graduate school following STEM degree completion.

Engineering Scholars' communities help develop well-rounded engineers and problem-solvers who are able to "think globally" as engineers are increasingly required to do. However, the communities would all be for naught if learning outcomes, and more specifically GPA and retention, were not improved. The most important aspect about Scholars programs at OSU is that students thrive academically. The impact is demonstrated by a 95\% retention rate of Scholars to the second year and 3.29 average GPA (2014 data). This compares to an $89.1 \%$ retention rate and a 2.95 average GPA for non-Scholars. More striking is the 6-year graduation rate of $87.9 \%$ for Scholars and $77.6 \%$ for non-Scholars.

While Scholars' community support structures were put in place to maximize the chances of successful outcomes for the students, one significant and perhaps obvious element of support is missing: financial aid. We believe financial support is an essential part of maximizing these students' probability of success. Without S-STEM support, Scholars at OSU do not receive any scholarship monies specifically related to their participation in the Scholars Program. That is not to say that these students do not have financial need - they do. Many of our students have a considerable gap between their ability to pay for their education and the cost of attending. This gap constitutes a financial need that has not gotten smaller over recent years at OSU. The total in-state cost of an undergraduate education (inclusive of tuition, fees, books, room and board and related expenses) was approximately $\$ 25,500$ in $2014-15$. This cost has risen $31 \%$ over the past 10 years, as state subsidies have decreased and the cost of delivering an education has risen.

Addressing this financial need is at the core of "HumanConnect", this S-STEM scholarship program that draws students entirely from the HES Program group who are academically 
qualified, yet also have financial need. Unmet financial need contributes to stress about debt incurred as a student, takes attention away from academics as students are forced to work increased hours to support themselves and can cause students to drop out of their academic programs altogether.

\section{Goals of HumanConnect}

The primary goals of the HumanConnect program are:

1) Positively impact retention and graduation rate of engineering students with financial need.

2) Improve academic performance relative to a control group.

\section{$\underline{\text { Methods }}$}

The first cohort of HumanConnect students was selected from HES in the 2013-14 academic year. (For the remainder of this communication, HES is used to refer to the subset of scholars who received the HumanConnect award and GES specifies the corresponding control group.) The awards were able to meet a significant portion of unmet financial need (on average $\$ 4500$ out of $\$ 11,500$ ) for 15 students (11 freshmen and 4 sophomores). Because the timing of the award was after the first semester had started, students from this first cohort were selected after their first semester was complete and it could be confirmed that they were in good standing in the HES program, including a minimum 3.0 GPA. The scholarship was then applied for the entire 2013-14 academic year. In order to establish the effect of the scholarship on program goals, for comparison purposes, a control group of 15 GES students was selected from the same academic year as HES with a comparable level of unmet financial need.

In the second year of the award, a new cohort of 15 HES students, all freshmen, was awarded scholarships before they were admitted to OSU, relying on high school GPA and standardized test scores to determine academic eligibility. The rationale for awarding the scholarship up front for the second cohort was to create a recruiting tool to positively influence the decision to attend for candidates who otherwise might not be able to afford a college education at all. In subsequent years, for both Cohorts 1 and 2, these scholarships continue to be renewed, covering up to 4 years of attendance, as long as students remain in good standing in the HES program and continue to experience significant unmet financial need as indicated by the FAFSA. Similarly, a second GES control group $(n=17)$ was selected to allow comparison to the second HES cohort.

The unmet need for both HES cohorts and GES control groups and the average HES scholarship award in 2014-15 are summarized in Table 1. 
Table 1: HES vs. GES - Average Unmet and HES Award - All Participants

\begin{tabular}{|l|c|c|}
\hline \multirow{2}{*}{} & \multicolumn{2}{|c|}{$\begin{array}{c}\text { HumanConnect } \\
\text { 2014-15 Data }\end{array}$} \\
\cline { 2 - 3 } & \multicolumn{2}{|c|}{ All Participants } \\
\cline { 2 - 3 } & $\begin{array}{c}\text { HES } \\
\mathbf{N = 3 0}\end{array}$ & $\begin{array}{c}\text { GES } \\
\mathbf{N = 3 2}\end{array}$ \\
\hline Unmet Need & $\$ 11,839$ & $\$ 10,750$ \\
\hline 2014-15 HES Scholarship & $\$ 4,417$ & NA \\
\hline Unmet Need Following HES Scholarship & $\$ 7,422$ & NA \\
\hline $\begin{array}{l}\text { Percent Unmet Need Met by HES } \\
\text { Scholarship }\end{array}$ & 37.3 & NA \\
\hline
\end{tabular}

In Spring 2015, students from both HES Cohorts 1 and 2 and both GES control groups were invited to complete an online survey to which 17 HES students and six GES students responded. The response rates are summarized by cohort in Table 2. Overall, the survey was completed by 23 of the 55 students across both HES and GES groups, representing a completion rate of 42 percent. To the extent possible, given the small numbers of students who responded to the survey, comparisons are made between HES and GES students. As well, online academic data was retrieved for all groups in order to gauge academic performance and progress. Finally, telephone interviews with the four project team members, faculty and staff associated with the HumanConnect program, were also conducted. The interviews covered their opinions about the impact of the scholarships on the awardees and issues related to project management, institutionalization, and sustainability of the HumanConnect initiative. All evaluation activities were conducted by Institutional Research Consultants, Ltd. (IRC), a Columbus area evaluation firm directed by Dr. Jan Upton and approved under IRB Protocol \# 2013B0625 at OSU.

Table 2: HES vs. GES - Spring 2015 Survey Response Rates

\begin{tabular}{|r|c|c|c|c|c|}
\hline & \multirow{2}{*}{$\begin{array}{c}\text { Original } \\
\text { Total }\end{array}$} & \multicolumn{2}{|c|}{ Active as of March } & & \\
\cline { 3 - 6 } & $\mathbf{2 0 1 5}$ & $\mathbf{2}$ & $\begin{array}{c}\text { Surveys } \\
\text { Received }\end{array}$ & $\begin{array}{c}\text { Response } \\
\text { Rate }\end{array}$ \\
\hline HES - Cohort 1 & 15 & $13^{\mathrm{a}}$ & 86.7 & 11 & 84.6 \\
\hline HES - Cohort 2 & 15 & 14 & 93.3 & 6 & 42.9 \\
\hline HES - TOTAL & $\mathbf{3 0}$ & $\mathbf{2 7}$ & $\mathbf{9 0 . 0}$ & $\mathbf{1 7}$ & $\mathbf{6 3 . 0}$ \\
\hline GES - Cohort 1 & 15 & 11 & 73.3 & 4 & 36.4 \\
\hline GES - Cohort 2 & 17 & 17 & 100.0 & 2 & 11.8 \\
\hline GES - TOTAL & $\mathbf{3 2}$ & $\mathbf{2 8}$ & $\mathbf{8 7 . 5}$ & $\mathbf{6}$ & $\mathbf{2 1 . 4}$ \\
\hline TOTAL & $\mathbf{6 2}$ & $\mathbf{5 5}$ & $\mathbf{8 8 . 7}$ & $\mathbf{2 3}$ & $\mathbf{4 1 . 8}$ \\
\hline \hline
\end{tabular}

${ }^{a}$ One student was not financially eligible in 2015-16 and consequently did not receive a scholarship award. However, this individual was retained in the cohort, as financial status could change in a future year. 


\section{Data and Results}

\section{Data from Academic Records}

Goal 1, described earlier, refers to graduation rate and retention in engineering at OSU. While the HumanConnect program just completed its second year and is not far enough along to have graduates, Table 3 summarizes retention statistics. At the end of Spring 2015, both HES and GES had similarly high overall rates of retention ( $90 \%$ and $91 \%$ respectively). By comparison, overall first year retention in the College of Engineering was 81\% for 2013-14.

Table 3: HES vs. GES - Retention at End of Spring 2015 by Cohort

\begin{tabular}{|c|c|c|c|c|c||}
\hline & Original & \multirow{2}{*}{$\begin{array}{c}\text { Left } \\
\text { Total }\end{array}$} & $\begin{array}{c}\text { Left } \\
\text { Engineering }\end{array}$ & \multicolumn{2}{c||}{$\begin{array}{c}\text { Retention } \\
\text { Spring 2015 }\end{array}$} \\
\hline HES - Cohort 1 & 15 & 0 & 0 & 15 & 100.0 \\
\hline HES - Cohort 2 & 15 & 3 & 0 & 12 & 80.0 \\
\hline HES - TOTAL & $\mathbf{3 0}$ & $\mathbf{3}$ & $\mathbf{0}$ & $\mathbf{2 7}$ & $\mathbf{9 0 . 0}$ \\
\hline GES - Cohort 1 & 15 & 1 & 0 & 14 & 93.3 \\
\hline GES - Cohort 2 & 17 & 0 & 2 & 15 & 88.2 \\
\hline GES - TOTAL & $\mathbf{3 2}$ & $\mathbf{1}$ & $\mathbf{2}$ & $\mathbf{2 9}$ & $\mathbf{9 0 . 6}$ \\
\hline
\end{tabular}

Goal 2 refers to academic performance for which we have chosen to use semester and cumulative GPA as indicators. Academic records (Table 4) showed that HES students had a slightly higher GPA in Autumn 2014, which rose in Spring 2015 (from 3.10 to 3.22). The GPA of the GES group, however, went down between Autumn 2014 and Spring 2015 (3.02 to 2.94). Although this difference was not statistically significant, it is noteworthy.

Table 4: HES vs. GES - Average GPAs - All Participants

\begin{tabular}{||l|c|c|}
\hline \multirow{2}{*}{} & \multicolumn{2}{|c|}{$\begin{array}{c}\text { HumanConnect } \\
\text { 2015 Data }\end{array}$} \\
\cline { 2 - 3 } & \multicolumn{2}{|c|}{ All Participants } \\
\cline { 2 - 3 } & HES & GES \\
& $\mathbf{N = 3 0}$ & $\mathbf{N = 3 2}$ \\
\hline AU14 GPA & 3.10 & 3.02 \\
\hline AU14 Cumulative GPA & 3.14 & 3.08 \\
\hline SP15 GPA & 3.22 & 2.94 \\
\hline SP15 Cumulative GPA & 3.16 & 3.01 \\
\hline
\end{tabular}


Of great interest is that both HES cohorts maintained a higher Spring 2015 GPA and cumulative average than did their respective GES control group (Table 5). Higher average GPAs for HES cohorts may suggest that the scholarship pushed recipients to achieve as part of maintaining eligibility. Note that GPAs for Cohort 2 are lower for both HES and GES groups. Recall that Cohort 2 was selected prior to admission to the university, based solely upon high school record.

Table 5: HES vs. GES - Average GPAs - By Cohort

\begin{tabular}{|l|c|c|c|c||}
\hline \multirow{2}{*}{} & \multicolumn{4}{|c|}{ HumanConnect } \\
& \multicolumn{3}{|c||}{ 2014-15 Data } \\
\cline { 2 - 5 } & \multicolumn{3}{|c||}{ GES } & \multicolumn{2}{c|}{ GES } \\
\cline { 2 - 5 } & Cohort 1 & Cohort 2 & Cohort 1 & Cohort 2 \\
& $\mathbf{N = 1 5}$ & $\mathbf{N = 1 5}$ & $\mathbf{N = 1 7}$ \\
\hline SP15 GPA & 3.32 & 2.97 & 3.22 & 2.68 \\
\hline SP15 Cumulative GPA & 3.32 & 2.95 & 3.27 & 2.81 \\
\hline
\end{tabular}

Further evidence of Cohort 2 (both HES and GES) academic struggle is highlighted in Table 6, which shows the number and percent maintaining a 3.0 GPA. Although the GPA for Cohort 1 was consistently above a 3.0, this was not the case for Cohort 2. Although not statistically significant, it is interesting that the proportion of HES Cohort 1 students maintaining a cumulative GPA of 3.0 or above is noticeably higher (80\%) compared to the GES Cohort 1 $(67 \%)$.

Table 6: HES vs. GES - Average Spring 2015 GPA and Cumulative by Cohort

\begin{tabular}{|c|c|c|c|c|}
\hline \multirow[b]{3}{*}{ Scholars Group } & \multicolumn{4}{|c|}{$\begin{array}{c}\text { HumanConnect } \\
\text { 2014-15 Data }\end{array}$} \\
\hline & \multicolumn{2}{|c|}{ Spring 2015 Above 3.0} & \multicolumn{2}{|c|}{ Cumulative GPA Above 3.0} \\
\hline & $\mathbf{N}$ & $\%$ & $\mathbf{N}$ & $\%$ \\
\hline HES - Cohort 1 & 12 & 80.0 & 12 & 80.0 \\
\hline HES - Cohort 2 & 5 & 33.3 & 6 & 40.0 \\
\hline GES - Cohort 1 & 11 & 73.3 & 10 & 66.7 \\
\hline GES - Cohort 2 & 8 & 47.1 & 8 & 47.1 \\
\hline
\end{tabular}

\section{Data from Surveys - Closed-ended Questions}

The self-reported employment data in Table 7 reveals that half of the respondents in both HES and GES were currently employed (53\% and 50\% respectively). The HES students averaged slightly more hours per week (11 compared to nine for the GES group). In Year 1, significantly more of the HES students were employed (69\% versus 30\%). It is noteworthy that none of the HES Cohort 2 students reported having a job, which lowered the overall proportion of those currently working. This difference may be due to having the scholarship from the onset of their first semester at OSU (Autumn 2014) compared to students in Cohort 1 who did not receive 
awards until the spring. Also of note is that five of the eight Cohort 1 students (63\%) who responded to both the Year 1 and Year 2 surveys reduced the number of hours they worked in Year 2.

Table 7: HES vs. GES - Employment Status and Average Hours Worked

\begin{tabular}{|c|c|c|c|c|}
\hline \multirow{3}{*}{$\begin{array}{l}\text { Are you currently employed? If yes, please } \\
\text { type in the average number of hours that you } \\
\text { are currently working each week. }\end{array}$} & \multicolumn{4}{|c|}{$\begin{array}{l}\text { HumanConnect } \\
\text { Spring } 2015 \text { Data }\end{array}$} \\
\hline & \multicolumn{2}{|c|}{$\begin{array}{c}\text { HES } \\
N=17\end{array}$} & \multicolumn{2}{|c|}{$\begin{array}{l}\text { GES } \\
N=6\end{array}$} \\
\hline & $\mathbf{N}$ & $\%$ & $\mathbf{N}$ & $\%$ \\
\hline Currently Employed & 9 & 52.9 & 3 & 50.0 \\
\hline Range of Hours Each Week & \multicolumn{2}{|c|}{$5-20$} & \multicolumn{2}{|c|}{$7-12$} \\
\hline Average Hours Each Week & \multicolumn{2}{|c|}{10.78} & \multicolumn{2}{|c|}{9.33} \\
\hline
\end{tabular}

Table 8 displays the reported impacts resulting from having a scholarship. All 17 of the HES students $(100 \%)$ indicated that having a scholarship reduced their financial stress and their parents' stress about money, which was significantly more than GES students ( $60 \%$ on both). Particularly poignant in this section of the survey is that $69 \%$ of HES students reported that the scholarship "Has enabled me to reduce the number of hours I work each week", as opposed to $33 \%$ for GES. Eighty-two percent of HES students confirmed that scholarships made it easier for them to focus on coursework compared to only 40 percent in the GES group. Three quarters (75\%) of the HES students reported that scholarships allowed them to pursue their preferred majors and made it possible for them to do research or participate in service learning opportunities (significantly higher than the GES group). While 60 percent of the GES students agreed that scholarships allowed them to pursue their preferred majors, no GES students indicated that the scholarships made it possible for them to pursue research or service learning projects, which was a statistically significant difference. Another significant gap between the two groups is reflected in the 55 percent of HES students who affirmed that scholarships had given them more time to research graduate schools, whereas no GES students indicated this impact.

Table 9 attempts to account for aspects of the living-learning community and its support structures, including the S-STEM scholarship, which positively affected class performance. All of the HES students said that being part of a living-learning community and first-year engineering cohort had at least "Some Impact" on their performance in their classes. Five of the six GES students (83\%) agreed. A statistically significant HES/GES difference is reflected in the number of students who indicated that access to a Scholars Community Advisor positively impacted their academic performance (88\% HES versus 33\% GES). It is possible that the greater opportunity for one-on-one contact with the HES advisor, since HES is a smaller Scholars community, contributed to the value HES students placed on this aspect. This HES/GES difference was also evident in Year 1. 
Table 8: HES vs. GES - Scholarship Recipients - Impacts from Scholarship ${ }^{a}$

\begin{tabular}{|l|c|c|c|c||}
\hline \multirow{2}{*}{$\begin{array}{l}\text { Mark the extent to which the following } \\
\text { impacts have ensued from having a }\end{array}$} & \multicolumn{3}{|c|}{$\begin{array}{c}\text { HumanConnect } \\
\text { Scholarship. Answer this question for your }\end{array}$} & \multicolumn{2}{|c|}{$\begin{array}{c}\text { HES } \\
\text { s.17 }\end{array}$} & \multicolumn{2}{c||}{ NES } \\
\cline { 2 - 5 } $\begin{array}{l}\text { Humanitarian Engineering Scholars } \\
\text { scholarship if you have one, otherwise answer } \\
\text { for your other scholarship(s). }\end{array}$ & N & \% & N & \% \\
\hline Has reduced my stress about money. & 17 & 100.0 & 3 & $60 . *^{* *}$ \\
\hline Has reduced my parents' stress about money. & 17 & 100.0 & 3 & $60 . *^{* *}$ \\
\hline $\begin{array}{l}\text { Has made it easier for me to focus on my } \\
\text { courses. }\end{array}$ & 14 & 82.4 & 2 & 40.0 \\
\hline Has allowed me to pursue my preferred major. & 12 & 75.0 & 3 & 60.0 \\
\hline $\begin{array}{l}\text { Has made it possible for me to pursue a research } \\
\text { or service learning opportunity that would } \\
\text { involve travel to another country. }\end{array}$ & 9 & 75.0 & 0 & $0.0 * *$ \\
\hline $\begin{array}{l}\text { Has enabled me to reduce the number of hours I } \\
\text { work each week. }\end{array}$ & 9 & 69.2 & 1 & 33.3 \\
\hline $\begin{array}{l}\text { Has given me more time to research career } \\
\text { options. }\end{array}$ & 10 & 62.5 & 1 & 20.0 \\
\hline $\begin{array}{l}\text { Has given me more time to research graduate } \\
\text { schools. }\end{array}$ & 6 & 54.5 & 0 & $0.0 *$ \\
\hline $\begin{array}{l}\text { Has enabled me to improve my grades or made } \\
\text { it easier to maintain already high grades. }\end{array}$ & 8 & 47.1 & 2 & 40.0 \\
\hline $\begin{array}{l}\text { Has enabled me to spend more time doing } \\
\text { service learning or volunteering. }\end{array}$ & 7 & 41.2 & 2 & 40.0 \\
\hline \hline
\end{tabular}

a Percent of participants who indicated "Significant Impact" or "Modest Impact." Percentages are based on those with valid response to item. "Not Applicable" responses were omitted. Statistically significant differences between the HES and GES groups based on distribution differences as measured by Chi-square test.

*Statistically significant difference with p-value $<.10$.

**Statistically significant difference with p-value $<.05$. 
Table 9: HES vs. GES - Positive Impacts on Performance in Classes ${ }^{a}$

\begin{tabular}{|c|c|c|c|c|}
\hline \multirow{3}{*}{$\begin{array}{l}\text { Please mark the extent to which you think } \\
\text { each item listed below has positively impacted } \\
\text { your performance in your classes. }\end{array}$} & \multicolumn{4}{|c|}{$\begin{array}{l}\text { HumanConnect } \\
\text { Spring } 2015 \text { Data }\end{array}$} \\
\hline & \multicolumn{2}{|c|}{$\begin{array}{c}\text { HES } \\
N=17\end{array}$} & \multicolumn{2}{|c|}{$\begin{array}{l}\text { GES } \\
N=6\end{array}$} \\
\hline & $\mathbf{N}$ & $\%$ & $\mathbf{N}$ & $\%$ \\
\hline $\begin{array}{l}\text { Being part of a living-learning community and } \\
\text { living in a common residence hall }\end{array}$ & 17 & 100.0 & 5 & 83.3 \\
\hline Being part of a first-year engineering cohort & 16 & 100.0 & 5 & 83.3 \\
\hline Humanitarian Engineering Scholars scholarship & 16 & 94.1 & \multicolumn{2}{|c|}{ Not Applicable } \\
\hline Other scholarships & 15 & 88.2 & 5 & 83.3 \\
\hline Access to Scholars Community Advisor & 15 & 88.2 & 2 & $33.3 * *$ \\
\hline Community service through Scholars Program & 13 & 76.5 & 3 & 50.0 \\
\hline Optional service learning course or trip & 8 & 72.7 & 2 & 50.0 \\
\hline Field trips/tours & 12 & 70.6 & 2 & 50.0 \\
\hline $\begin{array}{l}\text { Taking Humanitarian Engineering Scholars } \\
\text { Seminar (Scholar 1100) }\end{array}$ & 11 & 64.7 & \multicolumn{2}{|c|}{ Not Applicable } \\
\hline Humanitarian Engineering Capstone project & 2 & 50.0 & \multicolumn{2}{|c|}{ Not Applicable } \\
\hline $\begin{array}{l}\text { Serving on the Humanitarian Engineering } \\
\text { Scholars Leadership Council }\end{array}$ & 3 & 42.9 & \multicolumn{2}{|c|}{ Not Applicable } \\
\hline
\end{tabular}

a Percent of participants who indicated "Great Impact" or "Some Impact." Percentages are based on those with valid response to item. "Not Applicable" responses were omitted. Statistically significant differences between the HES and GES groups based on distribution differences as measured by Chi-square test.

$* *$ Statistically significant difference with $\mathrm{p}$-value $<.05$.

In 2014-15, a question was added to the survey pertaining to the role that the scholarship played in choosing to attend OSU (Table 10). (Recall that Cohort 2 was offered the HES scholarship prior to their enrollment.) Five of the six (83\%) indicated that it was least "somewhat important," including one who confirmed that it was "very important - the deciding factor in the decision." For the remaining student, it was still viewed as "a nice benefit but not a deciding factor."

\section{Table 10: HES Cohort 2 - Extent HES Scholarship Was a Factor in Attendance at OSU}

\begin{tabular}{|l|c|c||}
\hline \multirow{2}{*}{$\begin{array}{l}\text { To what extent was the Humanitarian Engineering Scholars } \\
\text { scholarship a factor in your decision to attend Ohio State }\end{array}$} & \multicolumn{2}{c|}{$\begin{array}{c}\text { HumanConnect } \\
\text { Spring 2015 Data }\end{array}$} \\
\cline { 2 - 3 } University? & $\begin{array}{c}\text { HES Cohort 2 Only } \\
\mathbf{N}=\mathbf{6}\end{array}$ \\
\cline { 2 - 3 } & $\mathbf{N}$ & $\mathbf{\%}$ \\
\hline It was very important - the deciding factor in the decision. & 1 & 16.7 \\
\hline It was somewhat important-one of many factors in the decision. & 4 & 66.7 \\
\hline It was a minor - a nice benefit but not a deciding factor. & 1 & 16.7 \\
\hline It was not a factor at all. & 0 & 0.0 \\
\hline
\end{tabular}




\section{Data from Surveys - Open-ended Questions}

Oftentimes the most compelling data lies less in the numbers and more in student answers to openended questions. The Year 2 survey proved to be no exception. When asked to describe what having a scholarship has meant for them, the difference in response between the HES and GES students points to the HumanConnect scholarship as having major benefits for the awardees, potentially enabling them to concentrate more fully on achieving success as engineering majors. Most HES students in both cohorts reported strong positive impacts related to reduced stress and the ability to stay focused on academics without the time-consuming pressure of outside employment. They described the HES scholarship as "a huge stress reliever" and "a blessing." For two HES students, the grant was a key factor in major job and educational decisions:

$<$ The scholarship> allowed me to focus less on working and figuring out where I'm going to get money to pay my expenses. It has allowed me to focus more on my schoolwork and future career options.

I can choose a major that has a significant work load and not worry as much about getting a part-time job to help pay for college. It also takes some stress off my parents.

Last year I worked off-campus 16 to 26 hours a week and my employers made me feel bad for not working more. The only reason I felt comfortable quitting was because I knew this HES Scholarship was there to help with my expenses.

Having a scholarship is nearly the main reason I am able to attend OSU. Without it, I wouldn't have the means to attend, so I am extremely grateful for scholarships that allow me to be here.

HES respondents also indicated that the scholarship motivated them to keep their grades up in order to remain eligible. Interestingly, the urgency to retain their eligibility for the award became a source of stress for two of them:

I have always expected $100 \%$ effort out of myself, but now I absolutely require myself to maintain above a 3.0 GPA, in fact, to far surpass it so I wouldn't need to worry about remaining eligible for this scholarship.

The scholarship encourages me to perform well in my classes in order to stay above the required 3.0 GPA.

Sometimes I really worry about my GPA dropping because I fear losing scholarships, which is arguably a good thing. However, it can be very worrisome when I try my hardest but don't always get the result I am looking for.

It has been a big relief to my family since we do not have to take out even more loans, but it has caused me stress during school because I know I have to do well to keep my scholarship. 


\section{$\underline{\text { Discussion and Conclusions }}$}

\section{Recipient Identification and Scholarship Timing}

In the two years of our present S-STEM award (Cohort 1: 2013-14 and Cohort 2: 2014-15), the way recipients were identified and the timing of their scholarship awards were approached differently. For Cohort 1, in part because the timing of the NSF award was after the start of fall semester, the recipients were identified after grades were recorded from the first semester of college. They still received a full-year scholarship amount scaled by their unmet financial need, but it was not applied until the beginning of spring semester. The important aspect is that these students were selected from a pool that had successfully completed one semester of engineering and earned at least a 3.0 GPA. In Cohort 2, we specifically wanted the scholarship to be a part of the student's aid package at the time they were notified of acceptance so that the scholarship could be part of their decision to attend the university, perhaps 'making the difference' between attending and not attending college. This turned out to not be the best idea, as recruitment was based (in addition to unmet financial need) on high school performance (GPA) and standardized test scores, which turn out to be a poorer predictor of success in college. Because of this difference in recruitment timing and strategy, HES Cohort 2 is more representative of the OSU College of Engineering as a whole in terms of first year GPA (2.95). Since retention in the HES program is based, among other things, upon maintaining a 3.0 GPA, a significant number of students from Cohort 2 ( 8 out of 15) were put on warning status after the first semester and 4 of them were dropped from the HumanConnect program after spring semester. This caused us to select several new recipients in autumn 2015, already in the second year of their program, to replace the Year 1 students who had been removed. Since the aim of S-STEM is to follow qualified students through to graduation (and career placement), then a better approach is to use the recruitment technique used for Cohort 1 and recruit after the first semester of college is completed successfully. Indeed other S-STEM recipients have noticed this challenge and have limited the amount of scholarship awards made to incoming freshmen².

The HumanConnect Program is meeting its goals, with retention data on par with the control group and above College norms and GPA data slightly superior to the control groups. The findings related to student stress levels supports the notion that the S-STEM scholarship serves to complete a 'triad' of support for these students that includes academic, social/emotional and financial components.

\section{Bibliography}

${ }^{1}$ NSF Scholarships in Science, Technology, Engineering, and Mathematics (S-STEM) Program Solicitation, 12529, National Science Foundation, Directorate for Education \& Human Resources, Division of Undergraduate Education.

${ }^{2}$ Brown, E. C., Farwell, M. A. and Kennedy, A. M., Writing and Implementing Successful NSF S-STEM Proposals, American Society for Engineering Education Annual Conference \& Exposition, Seattle, WA, June 14-17, 2015. 